\title{
Spatial inequality and polarisation in India
}

By

\section{Farhad Noorbakhsh}

\begin{abstract}
This paper analyses the extent of inequality amongst the major states of India over nearly two decades. It reviews various theoretical propositions for possible convergence and divergence and argues that while the evidence from the more developed countries supports the case of convergence the empirical evidence shows that the Indian states are on the course of divergence rather than convergence. The paper also investigates if the increasing inequality amongst the states have been coupled with polarisation. Some possible dimensions around which polarisation may have taken place are analysed of which some seem to be highly influential.
\end{abstract}

Keywords: Inequality, polarisation, regional inequality, India. 


\section{Introduction}

Most people think of a country as a homogenous economic, social and political entity, yet there may be vast differences between the regions within that country. The debate in the literature on spatial inequality is distinctly divided and more oriented towards the belief that the market mechanism will eventually ensure regional equality. The empirical literature is also divided but seems to suggest that while there may be some justification for such an optimism in the case of more developed countries, the evidence for developing countries so far, though scant, seems to suggest the opposite.

Spatial inequality within a number of developing countries is a major problem yet it has attracted little attention at the policymaking level and India does not seem to be an exception to this norm. Disparities amongst regions in India have been of main concern for a long time (Datt and Ravallion 1993). "Enormous variations in regional experiences and achievements" coupled with "the even sharper" contrasts "in some fields of social development” have resulted in remarkable internal diversities in India (Dreze and Sen 1995, p 45). Datt 1998 referring to India observes that "regional disparities in standards of living have been large.” (p 10). Furthermore the "long-term progress in raising rural living standards has been diverse across states in India.” (Datt and Ravallion 1998, p 34). Such disparities are regarded to be the reason for various states having different capacities for poverty reduction ( Ravallion and Datt 2002).

On the other hand Dreze and Srinivasan (1996) find some evidence of convergence, though weak, in the average per capita expenditure levels amongst the regions in India and note that the head-count index of rural poverty between 1972-73 and 1987-88 in almost all regions of India had declined though to different extents. Chronic and multidimensional poverty in some states have remained persistently high while some better-off as well as poor states succeeded in reducing this and closing the gap (Mehta and Shah 2003).

The National Human Development Report 2001 for India (2002) reveals considerable differences in human development and poverty between the states of India in 1981. The report notes wide regional disparities in the level of human development and observes that “The inter-state differences in human poverty are quite striking.” (PCGI 
2002, p 5). The report notes that while there have been improvements in the human development index and human poverty index during the 1980s, the inter-state disparities have persisted through the decade and the relative position of the states has practically remained the same. Noorbakhsh (2003) notes that some regional indicators provide little evidence of decreasing regional disparities in India.

The purpose of this paper is to contribute to the empirics of this debate by investigating the dynamics of inequality amongst the major states of India, to find out if there has been any tendency towards polarisation and to investigate its possible dimensions over time. The rest of this paper is organised as follows. Section 2 briefly reviews the theoretical debate and the empirical studies on spatial inequality. Section 3 investigates whether the major states in India are on the course towards convergence or divergence. Section 4 further studies the extent of inequality amongst the states. Section 5 contains an analysis of possible polarisation of inequality amongst the states. The following section studies some possible dimensions of polarisation and Section 7 concludes.

\section{Theoretical and empirical literature}

There is relatively little theoretical investigation on spatial inequalities in developing countries. Most theoretical models discussed in the literature are an extension of those on growth and inequality to spatial inequality sometimes to geographical regions and sometimes to regions within a country.

Starting with the classical economists, Ricardo's two sector model which mainly concentrated on growth and distribution within agriculture and industry addressed the shares of rent (returns to landowners in agriculture) and profits (returns to capitalists in industry) with wages remaining at subsistence level. The process of growth in Ricardo's model was smooth but at a declining rate eventually approaching the steady state of zero growth due to the diminishing returns in agriculture (Boyer 1996). Malthus saw the process of growth as an unbalanced process where population growth would result in excess labour supply. This coupled with the diminishing returns of fixed land resources would force wages back to the subsistence level. Marx also believed that capitalist development would inherently cause uneven distribution of 
income and capitalists have an incentive for pushing wages to the subsistence $\operatorname{level}^{1}$ (Martin and Sunley 1998, Dunford and Smith 2000).

The neoclassicals however, were more optimistic about market forces and postulated that regional inequality is a passing phase and that market forces would ensure that the returns to all factors of production would approach their marginal products. Regional inequality initially arises in the process of the allocation of resources but factor mobility and efficient market forces would eventually ensure regional equality (Smith 1975). However, this is based on the existence of fully competitive markets which are a relatively rare phenomena in most developing countries. The common explanation of classical and neoclassical economists seems to be resource endowment whether land based or industry (capital) based (Kaldor 1970). In Kaldor's view the resource endowment or location theory do not provide a clear explanation for the causes of divergent regional growth rates.

Alternatively the Lewis's labour-surplus model assumes the abundance of labour and the scarcity of other factors of production suggesting that inequality will initially rise but will fall as the country develops. This is consistent with Kuznets inverted U hypothesis that inequality would occur at the early stages of development but would ease as the economy develops. Along with these propositions are also the idea of the creation of growth poles for achieving regional growth. Growth pole dynamics and inverted-U hypothesis sustain that regional inequalities within developing countries will be eventually reduced through factor mobility.

Neo-Keynesians such as Harrod and Domar stated that the dynamics of equilibrium between the consumption and investment decisions would not necessarily lead to the long run full employment but rather would bring about an unstable growth path (Boyer 1996). In contrast neoclassicists such as Solow and Swan envisaged a much smoother growth path. In the presence of the fully competitive markets and the availability of similar technology with the same rate of investment every economy would grow at a similar rate determined by the exogenous technical progress and population growth. Given the constant returns to scale of the production function and

\footnotetext{
${ }^{1}$ Though according to Marx fall in the rate of profit eventually would lead to crises and the fall of capitalism to be replaced by socialism which will then results in improvement in returns to labour.
} 
the diminishing returns of capital the economies with lower level of initial productivity enjoy a higher rate of growth in productivity and as such will catch up with the more developed economies.

Contemporary work on explaining the process of catching up envisages two possible, and sometimes related, types of convergence. The $\beta$-convergence, where poor regions will tend to grow faster than the more developed regions (as the diminishing marginal returns to capital prevails in the latter regions) and $\sigma$-convergence concerning crossregional dispersion (inequalities) which would tend to decrease over time (Lucas 1988, Mankiw et al. 1992, Barro and Sala-I-Martin 1992, 1995).

On the other hand the opposing theories, dependency and structural change theories, postulate that regional inequality is an inevitable outcome of capital accumulation and profit maximisation; market forces tend to increase rather than decrease regional inequality. Myrdal's (1957) circular and cumulative causation thesis proposes that the creation of a favoured region may have its origin in a historical accident but there is a natural tendency for all economic activities with higher than average returns (such as industry, commerce, banking, insurance) and the know how with all the social amenities that go with these to cluster within such a core region with backwash effects on unfavoured regions. There may be some centrifugal spread effect (along the lines of trickle-down effects) but these do not point to the achievement of an equilibrium. On the contrary "even in a rapidly developing country many regions will be lagging behind, stagnating or becoming poorer; and there would be more regions in the last two categories if market forces alone were left to decide the outcome.” (Myrdal 1957, p 32).

Kaldor (1970, 1981) considered the Myrdal's principle of circular and cumulative causation synonymous to the existence of increasing returns to scale in processing activities which are mainly located in favoured regions. Referring to Allyn Young's paper (1928) he reiterates that the Adam Smith's principle of the division of labour takes place mainly through the continuous sub-division of industries into more specialised industries and hence the higher industrial expansion in the favoured region. The close association between the development of manufacturing industries 
and urbanisation ensures "a strong positive association between the growth of productivity and efficiency and the rate of growth in the scale of activities - the socalled Verdoorn Law.” (Kaldor 1970, p 340). Fast growing regions, relative to backward regions, experience higher increase in productivity coupled with a relative drop in efficiency wages and Kaldor (1970) argues that it is through this that the process of cumulative causation operates.

Similarly the structuralist and dependency theories, mainly discussed at inter-national but extended to intra-national level, maintain that the dependency of the periphery on core regions and the unbalanced transfer of values between them intensifies the regional inequality and that this is an inevitable outcome of capitalism (Kay 1989, Emmanuel 1972).

Expectation of convergence amongst countries or regions has been challenged on a number of grounds. These include the inherent limitation of the proposition that a region's growth is only related to its own background and is independent of the economy of which it is a part (Quah 1993). Furthermore, the proposition of the diminishing returns to capital and labour and their interregional spillovers, and the common access to the same technology are questioned (Dunford and Smith 2000).

The more radical contemporary economic geographers saw the process to be episodic associated with the expected periodic capitalist crises which would lead to the search for new locations for capital and new technology. The corollary of this is the growth of the new locations (regions) followed by the crises inherent in the capitalist system. Hence the process is neither convergent nor divergent but cyclical (Harvey 1982, Dunford 1988, Martin and Sunley 1998 and Dunford and Smith 2000).

In brief there are mainly two types of opposing theoretical models of regional inequality: convergence and divergence and these have been the focus of the more recent empirical studies on regional inequality. Most of these are cross-country studies and test the hypothesis of convergence (see for example Baumol 1986, Romer 1986, Baumol and Wolff 1988, Mankiw, Romer and Weil 1992, Barro and Sala-iMartin 1995, Sala-i-Martin 1996 and Dunford and Smith 1999). The general consensus is that there exists an evidence of convergence only amongst the richer 
countries. This provided support for the idea of convergence clubs in the sense that convergence may apply to groups of countries, which have similar initial conditions and structures. ${ }^{2}$ It is tempting to think that such similarities are more likely to exist amongst the regions within a country than amongst different countries.

The empirical intra-national studies on a number of countries provide some evidence on convergence within the richer countries. Barro and Sala-i-Martin 1995 give examples of both types of $\beta$-convergence and $\sigma$-convergence having taken place amongst different states in the USA, various prefectures in Japan and different regions within Germany, United Kingdom, France, Italy and Spain. Chatterji and Dewhurst (1996) conclude that convergence has taken place amongst counties/regions within the United Kingdom though its speed depended on economic conditions at the time. Coulombe (2003) suggests that since 1950 relative per capita income and human capital in 10 Canadian provinces did generally converge to a long-run steady state, though of different forms.

However, when it comes to developing countries the outcome seems to be different to those of the richer countries.

Fedorov (2002) highlights the growing regional inequalities in Russia in the1990s and concludes that regional inequality during the transitional period in Russia have increased significantly. Vanderpnye-Orgle (2002) discusses the growing trends in spatial inequalities in Ghana during the period of stabilisation and structural adjustment programmes - late 1980s to late 1990s and concludes that regional inequality increased during the first stages of reform period, followed by a short period of decline before resuming its increasing trend for the rest of the period to 1999. ${ }^{3}$ Wei and Kim (2002) in a study of inter-county inequality in Jiangsu province of China conclude that for the period of 1950-95 neither $\beta$-convergence nor $\sigma$ convergence took place in these counties. Riskin (1988) observes that substantial disparities between Chinese provinces in the 1950s became much more serious with industrialisation and argues that the regional disparities in terms of rural poverty

\footnotetext{
${ }^{2}$ For a review of club convergence and also the related issue of conditional convergence see Martin and Sunley 1998).

${ }^{3}$ The reader may be interested to note that Ghana is often quoted as the success story of reform programmes by the World Bank and IMF.
} 
remained high through time. Noorbakhsh (2002) observes remarkable inequality in economic and social aspects amongst the regions of Iran.

The Philippine Human Development Report 1997 (HDNUNDP) reports changes in the Human Development Index (HDI) across various provinces in the Philippines for 1990 to 1994 ranging from an increase of nearly 25\% to a decrease of nearly $4 \%$. The Human Development Report for Zimbabwe reports striking differences in the constituent indicators of human poverty index across its provinces ranging from 33\% to just over $6 \%$ for illiteracy and from just above $28 \%$ to less than $1 \%$ for no access to clean water (UNDP et al.1998). The Human Development Report of the I. R. of Iran 1999 (PBOUNDP, 1999) observes wide regional disparities within 26 provinces of Iran in terms of HDI and its gender adjusted indices and the human poverty index. Such disparities have been growing at an alarming rate leading to serious problems including migration with its associated problems from backward provinces to the more developed provinces. After highlighting the extent of regional disparities and the need to deal with them the report concludes that: "An improvement in human development in the I.R. of Iran as a whole requires not only a higher rate of economic growth but also a more equitable distribution of health and education facilities.” ( $p$ 23).

In brief the evidence seems to suggest that the experience of developing countries appears to be inconsistent with that of the richer countries.

\section{Convergence or divergence}

The literature on growth mainly focuses on two concepts of convergence. First, $\beta$ convergence (absolute convergence) where poorer regions have a tendency to grow faster and catch up with the richer regions, that is a reduction in inequality through higher growth in poorer regions. Second, $\sigma$-convergence (lower dispersion) where the dispersion of a measure of growth, for example per capita output or income, across the regions would tend to decrease through time, that is a reduction in inequality which can technically take place in a variety of ways including negative growth in the 
more affluent regions. ${ }^{4}$ It would be interesting to find out if the states of India have experienced any one of these types of convergence.

For the purpose of this study we have selected three regional indicators: Per capita net state domestic product (PCNDP), per capita consumption expenditure (PCCE) and inflation and inequality adjusted per capita consumption expenditure (IIAPCCE). The period covered is 1981/82 to 1997/98 for PCNSDP and 1983 to 1999/2000 for PCCE and IIAPCCE but not every year within these intervals. The data for PCCE and IIAPCCE are in rural and urban breakdown as well as combined. All Indian states with a population of above 1.5 million in 1991 for which the data was available are included in this study. The source of data is the National Human Development Report for India (PCGI 2002).

(i) $\beta$-convergence

We first test to see if $\beta$-convergence amongst the states of India has taken place. For this purpose we run the following growth regression derived from the neoclassical production function model (Barro and Sala-i-Martin1995, Martin and Sunley, 1998).

$\left(\frac{1}{T}\right) \log \left(\frac{y_{i t+T}}{y_{i t}}\right)=\alpha+\beta \log \left(y_{i t}\right)+u_{i t}$

where $y_{i t}=\frac{Y_{i t}}{\overline{Y_{t}}}$ is the ratio of the (income or consumption) variable in the $\mathrm{i}^{\text {th }}$ state to the average for the sample of states under consideration. $\left(\frac{1}{T}\right) \log \left(\frac{y_{i t+T}}{y_{i t}}\right)$ is the annualised growth of the variable concerned in the $\mathrm{i}^{\text {th }}$ state over the period of $\mathrm{t}$ and $\mathrm{t}+\mathrm{T}$. A value of $\beta$ in the range of $-1<\beta<0$ would be an evidence of $\beta$-convergence that is the nearer the value of $\beta$ to -1 the higher the speed of convergence and the nearer to zero the lower the speed of convergence. ${ }^{5}$ By implication zero means no convergence and a positive value for $\beta$ indicates a divergence.

\footnotetext{
${ }^{4}$ Martin and Sunley (1998) argue that the first type of convergence is a necessary but not a sufficient condition for having the second.

${ }^{5}$ Chaterji (1992) and Chaterji and Dewhurst (1996) distinguish between weak convergence where $\beta<0$, and strong convergence where $-2<\beta<0$.
} 
Table 1 shows the results for our indicators of PCNSDP, PCCE and IIAPCCE for combined values for states. The figures within brackets are the t-ratios.

Table 1. Growth regressions for production and consumption indicators (combined).

\begin{tabular}{|c|c|c|c|c|}
\hline Indicator growth & $\alpha$ & $\beta$ & $\mathrm{R}^{2}$ & $\mathrm{~F}$ \\
\hline PCNSDP 1981/82 to 1997/98 & $\begin{array}{c}-0.001 \\
(-0.535)\end{array}$ & $\begin{array}{c}0.010 \\
(1.678)\end{array}$ & 0.37 & 2.82 \\
\hline PCCE 1983 to 1999/2000 & $\begin{array}{c}-0.016 \\
(-0.722)\end{array}$ & $\begin{array}{c}0.045 \\
(3.987)^{* *}\end{array}$ & 0.69 & $15.90^{* *}$ \\
& $\begin{array}{c}-0.001 \\
\text { IIAPCCE 1983 to 1999/2000 }\end{array}$ & $\begin{array}{c}0.012 \\
(-0.300)\end{array}$ & 0.21 & 0.79 \\
\hline
\end{tabular}

** Significant at the $1 \%$ level.

* Significant at the $5 \%$ level.

As can be seen from Table 1 there is no evidence of $\beta$-convergence. If anything the results demonstrate a divergence as $\beta$ is positive, though only significant at $1 \%$ level in the case of PCCE; $\beta$ s for PCNSDP and IIAPCCE are positive but not significantly different from zero.

We also tried the growth regression for consumption and adjusted consumption for rural and urban areas. Although convergence of rural or urban areas of different states is more difficult to envisage within the existing administrative framework this breakdown, nevertheless, would allow us to see the dynamics of rural and urban areas separately which could be useful for policy making purposes. Table 2 presents the results for the rural/urban breakdown.

Table 2. Growth regressions for 1983 to 1999/2000 for PCCE and IIAPCCE (rural and urban areas).

\begin{tabular}{|l|c|c|c|c|}
\hline \multicolumn{1}{|c|}{ Indicator } & $\alpha$ & $\beta$ & $\mathrm{R}^{2}$ & $\mathrm{~F}$ \\
\hline PCCE - Rural & $\begin{array}{c}-0.001 \\
(-0.440)\end{array}$ & $\begin{array}{c}0.028 \\
(2.28)^{*}\end{array}$ & 0.47 & $5.22^{*}$ \\
\hline PCCE - Urban & $\begin{array}{c}-0.001 \\
(-0.285)\end{array}$ & $\begin{array}{l}0.019 \\
(1.14)\end{array}$ & 0.26 & 1.30 \\
\hline IIAPCCE - Rural & $\begin{array}{c}-0.000 \\
(-0.002)\end{array}$ & $\begin{array}{c}-0.048 \\
(-3.40)^{* *}\end{array}$ & 0.63 & $11.53^{* *}$ \\
\hline IIAPCCE - Urban & -0.000 & 0.003 & 0.05 & 0.04 \\
& $(-0.166)$ & $(0.196)$ & & \\
\hline
\end{tabular}

** Significant at the $1 \%$ level.

* Significant at the $5 \%$ level.

As can be seen from Table $2 \beta$ is positive and significant at $5 \%$ level for PCCE in rural areas. If anything this is an evidence of divergence. However, this coefficient for the gini and inflation adjusted per capita consumption (IIAPCCE) in rural areas is 
negative and significant at $1 \%$ level. This is an evidence of convergence though its speed is very low as the coefficient is nearer to zero than -1. This is in line with the results of the study by Dreze and Srinivasan (1996) in which they find an evidence of weak convergence in the average per capita expenditure at rural level amongst the Indian regions. As for urban areas we see no evidence of convergence as the positive $\beta$ coefficients signal the opposite, though none are significant.

(ii) $\sigma$-convergence

As we mentioned above this kind of convergence postulates that cross-regional dispersion (inequalities) would tend to decrease over time. If the variance of the variable concerned is smaller than the same in the initial period then this type of convergence has taken place. That is $\sigma_{\mathrm{yt}+\mathrm{T}}<\sigma_{\mathrm{yt}}$ indicates the existence of $\sigma$ convergence and vice versa.

We have selected three measures for investigating such a possible convergence: the coefficient of variation (CV) which is the ratio of the standard deviation to the mean of distribution, standard deviation of $\log \left(\mathrm{y}_{\mathrm{it}}\right)$ and also gini coefficient (GiniC) as a measure of dispersion amongst the states. ${ }^{6}$

Table 3 presents the results for PCNSDP. The measures are computed for the years for which data is available in order to see the dynamic evolvement of per capita production over the period.

\footnotetext{
${ }^{6}$ The GiniC coefficient has been computed as follows:$$
\text { GiniC }=\frac{2 \operatorname{cov}\left(y, r_{y}\right)}{N \bar{y}}
$$

where $\operatorname{cov}\left(y, r_{y}\right)$ is the covariance of indicator y and ranks of all states according to $\mathrm{y}$ and $\bar{y}$ is the mean of y (see Pyatt et al., 1980). It must be pointed out that this in fact is a measure of the concentration (dispersion) of indicator y, hence we called it GiniC in order to distinguish it with the population-weighted Gini coefficient which we will employ later in the paper.
} 


\begin{tabular}{lccc}
\multicolumn{4}{l}{ Table 3. Measures of } \\
\hline Year & CV & SD $\operatorname{Sog}\left(y_{i t}\right)$ & GiniC \\
\hline $1981-82$ & 0.4194 & 0.3590 & 0.2468 \\
$1983-84$ & 0.3772 & 0.3307 & 0.2240 \\
$1991-92$ & 0.4832 & 0.4181 & 0.2877 \\
$1993-94$ & 0.4898 & 0.4384 & 0.2984 \\
$1997-98$ & 0.4715 & 0.4515 & 0.3010 \\
\hline
\end{tabular}

CV measure in Table 3 shows a tendency towards convergence for 1983-84. This is followed by a considerable divergence for 1991-92 and 1993-94 followed by a small drop in 1997-98. If anything this oscillation supports the views of the more radical economic geographers proposing that the process is episodic rather than converging or diverging. However, the magnitude of increases in CV outweighs the drops. Over the entire period this measure reflects a clear divergence and a rise in inequality. The standard deviation of $\log \left(y_{i t}\right)$ shows a slight drop for 1983-84 followed by a considerable increase for 1991-92 followed by increases for the remainder of the period. GiniC shows an initial tendency towards convergence followed by consistent divergence through the rest of the period. Once again a remarkable increase in inequality overall.

Table 4 presents measures of dispersion for per capita consumption expenditure indicators, PCCE and also IIAPCCE. As mentioned before the data for these indicators of welfare is available by rural-urban breakdown as well as combined for the states. For PCCE the CV measure for rural areas shows a notable divergence for 1993-94 as compared to 1983, followed by a comparatively small move towards convergence for the 1999-2000. The same pattern is repeated for urban and combined PCCE. However, the standard deviation of $\log \left(y_{i t}\right)$ has increased steadily through the period for rural and combined data with a considerable increase for urban data in 1993-94 followed by a small drop for 1999-2000. GiniC reflects a constant increase in every period for rural, urban and combined PCCE though at different rates. Overall our measures provide more support for the case of divergence than for convergence.

As for IIAPCCE the results for CV, $\log \left(y_{i t}\right)$ and GiniC measures for rural, urban and combined indicators clearly point towards continuing divergence amongst the states with some relatively minor drops in CV urban and GiniC rural in the intermediate period. 
Table 4. Measures of $\sigma$-convergence for PCCE and IIAPCCE

\begin{tabular}{|c|c|c|c|c|c|c|c|c|c|}
\hline Year & $\begin{array}{c}\text { CV } \\
\text { Rural }\end{array}$ & $\begin{array}{c}\text { CV } \\
\text { Urban }\end{array}$ & $\begin{array}{c}\mathrm{CV} \\
\text { Combined }\end{array}$ & $\begin{array}{c}\mathrm{SD} \\
\log \left(y_{i t}\right) \\
\text { Rural }\end{array}$ & $\begin{array}{c}\text { SD } \\
\log \left(y_{i t}\right) \\
\text { Urban }\end{array}$ & $\begin{array}{c}\mathrm{SD} \\
\log \left(y_{i t}\right) \\
\text { Combined }\end{array}$ & $\begin{array}{l}\text { GiniC } \\
\text { Rural }\end{array}$ & $\begin{array}{l}\text { GiniC } \\
\text { Urban }\end{array}$ & $\begin{array}{c}\text { GiniC } \\
\text { Combined }\end{array}$ \\
\hline \multicolumn{10}{|l|}{ PCCE: } \\
\hline 1983 & 0.2217 & 0.1782 & 0.2151 & 0.2048 & 0.1646 & 0.1979 & 0.1390 & 0.1091 & 0.1320 \\
\hline 1993-1994 & 0.2830 & 0.2361 & 0.3083 & 0.2535 & 0.2124 & 0.2594 & 0.1723 & 0.1394 & 0.1735 \\
\hline 1999-2000 & 0.2749 & 0.2186 & 0.3060 & 0.2642 & 0.2113 & 0.2795 & 0.1793 & 0.1395 & 0.1870 \\
\hline \multicolumn{10}{|l|}{ IIAPCCE: } \\
\hline 1983 & 0.2137 & 0.1692 & 0.2010 & 0.2008 & 0.1568 & 0.1893 & 0.1369 & 0.1034 & 0.1281 \\
\hline 1993-1994 & 0.2360 & 0.1665 & 0.2273 & 0.2056 & 0.1572 & 0.1969 & 0.1356 & 0.1054 & 0.1291 \\
\hline $1999-2000$ & 0.2479 & 0.1848 & 0.2439 & 0.2293 & 0.1793 & 0.2250 & 0.1565 & 0.1192 & 0.1519 \\
\hline
\end{tabular}

\section{Population-weighted measures of regional inequality}

The measures considered so far were for investigating the possible occurrence of convergence as this particular strand of literature on inequality and convergence postulates. However, these measures assess the degree of concentration between the states without taking into account that the spread of population amongst the states varies. It may well be the case that the less developed states are more populated which makes the situation more critical and vice versa.

We have employed two measures of inequality, which take into account the population share of each state, for investigating the extent and dynamics of inequality amongst the states of India. These measures are the Lorenz-consistent Gini coefficient (GiniP) and the Generalized Entropy (GE) set of measures which are also Lorenz-consistent (Cowell, 1995, Shorroks 1980, 1984 and Fedorov 2002). The first one measuring inequality amongst the states can be presented as:

$\operatorname{GiniP}=\frac{1}{\mu} \sum_{i=1}^{R} \sum_{j=1}^{R} f\left(y_{i}\right) f\left(y_{j}\right)\left|y_{i}-y_{j}\right|$

where $y_{i}$ is the value of the indicator in state $\mathrm{i}, f\left(y_{i}\right)$ is the population share of state $\mathrm{i}$ in total population and $\mu$ is the mean value for the indicator under consideration.

The GE measures given below are sensitive to various parts of the distribution depending on the selected value for c. 


$$
\begin{aligned}
& \sum_{i=1}^{R} f\left(y_{i}\right)\left[\left(\frac{y_{i}}{\mu}\right)^{c}-1\right], \quad c \neq 0,1 \\
& \mathrm{GE}=\sum_{i=1}^{R} f\left(y_{i}\right)\left(\frac{y_{i}}{\mu}\right) \log \left(\frac{y_{i}}{\mu}\right), \quad c=1 \\
& \sum_{i=1}^{R} f\left(y_{i}\right) \log \left(\frac{\mu}{y_{i}}\right), \quad c=0
\end{aligned}
$$

where all variables are as defined above. We have used GE for c $=0$ which is the mean logarithm deviation more sensitive to lower values of the index i.e. the bottom part of the distribution. ${ }^{7}$

Table 5 presents the population weighted results for PCNSDP. GiniP, which is sensitive to all parts of the distribution, demonstrates a depressing situation. When we take the distribution of population amongst the states into account there has been a steady increase in inequality throughout the period. This implies that more populated states are adversely affected by regional inequality continually. GE measure, sensitive to the lower part of the distribution, shows an initial drop in inequality in 1983-84 followed by significant increases in 1991-92 and 1993-94 followed by a relatively small drop in inequality in the last period, a rather episodic pattern.

\begin{tabular}{lcc}
\multicolumn{3}{l}{ Table 5. Measures of inequality for } \\
\hline Year & GiniP & GE $(\mathrm{c}=0)$ \\
\hline $1981-82$ & 0.2811 & 0.0878 \\
$1983-84$ & 0.2820 & 0.0766 \\
$1991-92$ & 0.3368 & 0.0998 \\
$1993-94$ & 0.3859 & 0.1020 \\
$1997-98$ & 0.4325 & 0.0982 \\
\hline
\end{tabular}

Table 6 presents the population-weighted results for PCCE and IIAPCCE. The dynamics of inequality as reflected by GiniP is alarming. Taking the population dispersion into account results in higher inequality in welfare in all periods for rural, urban and combined PCCE, while the increase is relatively higher for urban and combined regional data.

\footnotetext{
${ }^{7}$ We have used GE measure for $\mathrm{c}=0$ as this lends itself better to decomposition later in the paper. It must be also said that this version is the Theil's Entropy index which is much more frequently employed in the empirical literature.
} 
Table 6. Measures of inequality for PCCE and IIAPCCE

\begin{tabular}{lcccccc}
\hline Year & $\begin{array}{c}\text { GiniP } \\
\text { Rural }\end{array}$ & $\begin{array}{c}\text { GiniP } \\
\text { Urban }\end{array}$ & $\begin{array}{c}\text { GiniP } \\
\text { Combined }\end{array}$ & $\begin{array}{c}\text { GE(c=0) } \\
\text { Rural }\end{array}$ & $\begin{array}{c}\text { GE(c=0) } \\
\text { Urban }\end{array}$ & $\begin{array}{c}\text { GE(c=0)C } \\
\text { Combined }\end{array}$ \\
\hline PCCE: & & & & & & \\
1983 & 0.1270 & 0.1286 & 0.1457 & 0.0633 & 0.0223 & 0.0520 \\
1993-1994 & 0.1466 & 0.1724 & 0.1791 & 0.0734 & 0.0253 & 0.0611 \\
1999-2000 & 0.1708 & 0.1958 & 0.2142 & 0.0802 & 0.0251 & 0.0699 \\
IIAPCCE: & & & & & & \\
1983 & 0.1177 & 0.1297 & 0.1358 & 0.0655 & 0.0304 & 0.0559 \\
$1993-1994$ & 0.1191 & 0.1429 & 0.1386 & 0.0639 & 0.0319 & 0.0528 \\
$1999-2000$ & 0.1432 & 0.1516 & 0.1675 & 0.0739 & 0.0376 & 0.0633 \\
\hline
\end{tabular}

The results for IIAPCCE unambiguously point towards the increasing inequality amongst the states for rural, urban and combined data. In particular GiniP shows a relatively high increase for the more recent period.

The results for GE measure, sensitive to the lower section of distribution, for PCCE show notable increases in regional disparities during the decade of 1983 to 1993-94 followed by further increase up to 1999-2000 for almost all rural, urban and combined data, though relatively higher increases are for the rural and combined data. For IIAPCCE there is a slight drop in inequality from 1983 to 1993-94 for the rural and combined data and an increase for the urban areas. However, there has been a considerable increase for all three from 1993/94 to 1999/2000.

Overall our population-weighted results seem to indicate an increase in spatial inequality and provide more support for the case of divergence than convergence.

\section{Regional Polarisation}

The measures discussed above reflect the regional distribution of our indicators of production and consumption but do not show the degree of concentration in clusters of regions. The more recent literature on inequality distinguishes between inequality and polarisation. The latter is the phenomenon of disappearing middle class and clustering around extremes in a distribution, which may get worse over time. ${ }^{8}$ Polarisation in the context of regions may be described as a situation where there are groups of regions at the extremes of the distribution with high intra-group

\footnotetext{
${ }^{8}$ See for example Esteban and Ray (1994) and Wolfson (1994 and 1997) on the concept and measurement, Zhang and Kanbur, (2001) and Fedorov (2002) on the application of the recommended measures.
} 
homogeneity but with a high inter-group heterogeneity. This reflects a different feature of the distribution than that of the inequality. Technically speaking, an equalising transfer of welfare, of the Pigou-Dalton type, from a region above the median of the distribution to a region below the median would reduce inequality and polarisation, provided that none of the regions move to the other side of the median because of the transfer. However, if such a transfer was from a region on one side of the median to another region on the same side then inequality would decrease but polarisation would increase (Wolfson 1997).

Esteban and Ray (1994) link the phenomena of polarisation in a society to the generation of tensions and social unrest and social conflict. ${ }^{9}$ In the context of regions the proposed convergence of regions may take place around local means at the extremes of the distribution as opposed to the global mean. That is regions will cluster around the highly developed and highly backward poles, the case of a clear division. Esteban and Ray (1994) propose an index for measuring polarisation based on two characteristics of the clusters: identification as measured by the population of each cluster and alienation as measured by the difference between the clusters.

The idea is that the size of cluster carries weight in terms of identification and alienation. Consider that Bihar had the lowest per capita consumption expenditure of nearly Rupees 100 per month in 1983 with Delhi having the highest of nearly Rupees 230. The difference between these figures reflects the alienation of these states and the identification comes from the sizes of population in Bihar (70 million) and Delhi(just above 6 million), that is the sense of identification increases as more people are in the same category. Now consider that in 1999-2000 a number of states have formed a cluster around Bihar and Delhi. That is the per capita consumption expenditure in Orissa, Bihar, Assam, Madhya Pradesh and Uttar Pradesh with a combined population of 322 million is low and more or less the same while the same for Delhi, Goa, Kerala and Punjab with a combined population of 71 million is high and form a cluster. In this case polarisation has increased. The inter-group difference reflects the alienation and the sizes of population in these two groups reflect the identification.

\footnotetext{
${ }^{9}$ See Esteban and Ray (1994) for an excellent discussion on the link between polarisation and social division and conflict.
} 
We employ two of the more commonly used measures of polarisation in recent literature. First the Esteban and Ray index, which is the product of the functions of identification and alienation.

$$
E R=A \sum_{i=1}^{R} \sum_{j=1}^{R} \pi_{i}^{1+\alpha} \pi_{j}\left|y_{i}-y_{j}\right|
$$

where $\mathrm{A}$ is a normalisation scalar, $\mathrm{R}$ the number of states, $\pi_{i}$ and $\mathrm{y}_{\mathrm{i}}$ are the population size and the value of the characteristic (indicator) for state i, respectively. The parameter $\alpha$ reflects the degree of polarisation whose range is between 0 and 1.6, where for $\alpha=0$ the ER index is equivalent to Gini coefficient as can be seen from comparing equations (2) and (4). The higher $\alpha$ the higher the weight attached to polarisation. We set $\alpha=1.5$ in order to give a high weight to polarisation. ${ }^{10}$

The second measure of polarisation we employ is the Wolfson index, which is based on the Lorenz curve and derived from the Gini coefficient. (Wolfson 1997). It can be written as:

$W=2(2 T-G i n i) /(m / \mu)$

where $\mathrm{T}=0.5-\mathrm{L}(0.5)$ and $\mathrm{L}(0.5)$ indicates the share of the bottom half of regions of the index, Gini is the Gini coefficient of the distribution, $\mathrm{m}$ and $\mu$ are the median and mean respectively.

Table 7 displays the measures of polarisation for PCNSDP. Both ER and W measures show a steady increase in polarisation with the exception of ER for 1983-84 which shows a slight decrease. The pace of increase as displayed by both measures is rather high.

\footnotetext{
${ }^{10}$ This is the most common value employed in the empirical literature on polarisation, for example see Zhang and Kanbur (2001) and Fedorov (2002).
} 
Table 7. Measures of polarisation for PCNSDP

\begin{tabular}{lcc}
\hline Year & ER & W \\
\hline $1981-82$ & 0.1689 & 0.0344 \\
$1983-84$ & 0.1632 & 0.0882 \\
$1991-92$ & 0.2705 & 0.1018 \\
$1993-94$ & 0.2952 & 0.1118 \\
$1997-98$ & 0.3408 & 0.1417 \\
\hline
\end{tabular}

As can be seen from Table 8 both ER and W measures display a much higher degree of polarisation in PCCE for rural, urban and combined data. The relative magnitude of increase for the entire period is very high. The ER results for IIAPCCE reveal increases through the time though of a lesser magnitude while the $\mathrm{W}$ measure reveals some improvements in 1993-1994 followed by an increase for rural and combined data.

Table 8. Measures of polarisation for PCCE and IIAPCCE

\begin{tabular}{lcccccc}
\hline Year & $\begin{array}{c}\text { ER } \\
\text { Rural }\end{array}$ & $\begin{array}{c}\text { ER } \\
\text { Urban }\end{array}$ & $\begin{array}{c}\text { ER } \\
\text { Combined }\end{array}$ & $\begin{array}{c}\text { W } \\
\text { Rural }\end{array}$ & $\begin{array}{c}\text { W } \\
\text { Urban }\end{array}$ & $\begin{array}{c}\text { W } \\
\text { Combined }\end{array}$ \\
\hline PCCE: & & & & & & \\
1983 & 0.0065 & 0.0062 & 0.0066 & 0.0589 & 0.0334 & 0.0325 \\
1993-1994 & 0.0192 & 0.0242 & 0.0220 & 0.0619 & 0.0415 & 0.0494 \\
1999-2000 & 0.0334 & 0.0460 & 0.0419 & 0.0911 & 0.0446 & 0.0688 \\
IIAPCCE: & & & & & & \\
1983 & 0.0045 & 0.0042 & 0.0046 & 0.0716 & 0.0303 & 0.0522 \\
1993-1994 & 0.0045 & 0.0056 & 0.0048 & 0.0349 & 0.0475 & 0.0350 \\
1999-2000 & 0.0057 & 0.0070 & 0.0064 & 0.0729 & 0.0447 & 0.0613 \\
\hline
\end{tabular}

Overall the results reveal considerable increases in polarisation through the period amongst the Indian states.

\section{Dimensions of Polarisation}

Measures discussed above provide us with information about the existence, dynamics and degree of polarization without telling us much about the nature of polarization. It would be interesting to find out if polarization has some meaningful dimensions. Has polarization taken place around specific characteristics acting as poles? States may have been clustered around a dimension common to them. This may provide us with more information about the nature of polarization.

Kanbur and Zhang (1999, 2001) have proposed an index for measuring polarization around a priori determined dimensions which may tell us more about the nature of the process. This fits well with the hypothesis of convergence which relates the reasons 
for convergence to a priori existing conditions in regions (countries). Their index is derived from GE measure (equation 3) and is based on the property of GE being additively decomposable. ${ }^{11}$

Kanbur and Zhang (KZ) index is derived by first decomposing the GE measure of inequality into within-group and between-group inequality. For K exogenously given groups, as determined by an a priori dimension, the GE measure of inequality I for indicator y can be decomposed into additively within-group and between-group segments:

$$
\begin{aligned}
& I(y)=\sum_{g=1}^{K} w_{g} I_{g}+I\left(\mu_{1} e_{1}, \ldots, \mu_{K} e_{K}\right) \\
& f_{g}\left(\frac{\mu_{g}}{\mu}\right)^{c} \quad c \neq 0,1 \\
& w_{g}=\quad f_{g}\left(\frac{\mu_{g}}{\mu}\right) \quad c=1 \\
& f_{g} \quad c=0
\end{aligned}
$$

Where $\mathrm{I}_{\mathrm{g}}$ is inequality in the $\mathrm{g}^{\text {th }}$ group, $\mu_{\mathrm{g}}$ is the mean of the $\mathrm{g}^{\text {th }}$ group, $\mathrm{e}_{\mathrm{g}}$ is a vector of 1 's of length $n_{g}$ (where $n_{g}$ is the population of the $g^{\text {th }}$ group) and $f_{g}$ is the population share of the $\mathrm{g}^{\text {th }}$ group.

This decomposition makes it possible to detect the relative contribution of each component to inequality. (( $\left.\mathrm{w}_{\mathrm{g}} \mathrm{I}_{\mathrm{g}} / \mathrm{I}(\mathrm{y})\right) * 100$ is the percentage contribution of the $\mathrm{g}^{\text {th }}$ within-group inequality to total inequality while $\left(\mathrm{I}\left(\mu_{1} \mathrm{e}_{1}, \ldots, \mu_{\mathrm{K}} \mathrm{e}_{\mathrm{K}}\right) / \mathrm{I}(\mathrm{y})\right)^{*} 100$ is the percentage contribution of between-group inequality to total inequality. The $\mathrm{KZ}$ index is the ratio of the first component to the second in equation $(6)^{12}$; more formally:

$$
K Z=\frac{\text { between }- \text { group inequality }}{\text { within }- \text { group inequality }}=\frac{I\left(\mu_{1} e_{1}, \ldots, \mu_{K} e_{K}\right)}{\sum_{g=1}^{K} w_{g} I_{g}}
$$

\footnotetext{
${ }^{11}$ For this property and the relevant discussion and formalisation of the decomposition see Shorrocks (1980, 1984).

${ }^{12}$ Fedorov (2002) proposes a modified version of $\mathrm{KZ}$ index which is the ratio of the between-group inequality to total inequality: $I\left(\mu_{1} e_{1}, \ldots, \mu_{K} e_{K}\right) / I(y)$.
} 
A useful benchmark for this index is 1 where the contributions of both types of inequality to total inequality are the same.

Two types of dimensions can be envisaged for the purpose of decomposition: static (where the corresponding value in the initial period is used for grouping the states through the period) and dynamic (where the corresponding value in the current period is used for grouping the states). Such a distinction corresponds well with the hypothesis of convergence, bearing in mind that convergence is basically the reduction of inequalities. Supporters of convergence hypothesis argue that convergence and its speed are related to initial conditions and structures present in regions (countries). While the initial condition is a static concept changes in structure over time are dynamic by nature. Most empirical studies on the dimensions of polarisation within the regions of a developing country have taken dimensions which are static by nature and, in the context of the convergence argument, mainly relevant to the initial conditions (for example see Kanbur and Zhang 1999, Zhang and Kanbur 2001, Fedorov 2002, Vanderpuye-Orgle 2002).

At the outset it should be noted that the selection of the dimensions is much restricted by the availability of data at the state level. For our dimensions we have employed three measures of literacy and quality of education, a measure of urbanisation, two measures of poverty, a social measure, a measure of health and the human development index as our dynamic poles around each of which polarisation may have taken place. In addition for a particular reason discussed below we have looked at the percentage of plan expenditure in rural and social sectors as an extra dimension for possible polarisation. For each of these dimensions we have categorised states into two groups: those with a value below the average for India and those above. ${ }^{13}$

Table 9 shows the results for the dynamic dimensions for PCNSDP variable. Withingroup and between-group contributions to inequality are expressed as percentages of total inequality. The $\mathrm{KZ}$ index is also provided, it must be noted that the modified $\mathrm{KZ}$ index (MKZ) suggested by Fedorov (2002) (see footnote 12) is in effect the

\footnotetext{
${ }^{13}$ The reader may wish to note that this is a rather soft criteria for grouping as we expect a wider spread around the mean value therefore a higher degree of polarisation around the selected dimensions should be regarded as a more serious case.
} 
percentage contribution of between-group inequality to total inequality which is also provided in Table 9 (entitled 'Between')

Table 9. Dynamic polarisation of states for PCNSDP - percentage within-group and between-group contributions to total inequality and KZ index

\begin{tabular}{|c|c|c|c|c|c|c|c|c|c|}
\hline Year & \multicolumn{3}{|c|}{ Literacy } & \multicolumn{3}{|c|}{ Female Literacy } & \multicolumn{3}{|c|}{ Pupil-Teacher ratio } \\
\hline & Within & Between & $\mathrm{KZ}$ index & Within & Between & $\mathrm{KZ}$ index & Within & Between & $\mathrm{KZ}$ index \\
\hline $1981-82$ & 48 & 52 & 1.08 & 68 & 32 & 0.47 & 83 & 17 & 0.20 \\
\hline $1983-84$ & 48 & 52 & 1.08 & 66 & 34 & 0.52 & 79 & 21 & 0.27 \\
\hline 1991-92 & 39 & 61 & 1.56 & 39 & 61 & 1.56 & 91 & 9 & 0.10 \\
\hline $1993-94$ & 34 & 66 & 1.94 & 34 & 66 & 1.94 & 93 & 7 & 0.08 \\
\hline $1997-98$ & 25 & 75 & 3.00 & 27 & 73 & 2.70 & 81 & 19 & 0.23 \\
\hline \multirow[t]{3}{*}{ Growth (\%) } & -47.92 & 44.23 & 177.78 & -60.29 & 128.13 & 474.47 & -0.02 & 11.76 & 15.00 \\
\hline & \multicolumn{3}{|c|}{ Urbanisation } & \multicolumn{3}{|c|}{ Poverty } & \multicolumn{3}{|c|}{$\begin{array}{l}\text { Rural \& Social } \\
\text { Expenditure }\end{array}$} \\
\hline & Within & Between & $\mathrm{KZ}$ index & Within & Between & $\mathrm{KZ}$ index & Within & Between & $\overline{K Z}$ index \\
\hline $1981-82$ & 73 & 27 & 0.37 & 42 & 58 & 1.38 & 74 & 26 & 0.35 \\
\hline $1983-84$ & 72 & 28 & 0.39 & 38 & 62 & 1.63 & 80 & 20 & 0.25 \\
\hline $1991-92$ & 77 & 23 & 0.30 & 49 & 51 & 1.04 & 79 & 21 & 0.27 \\
\hline $1993-94$ & 71 & 29 & 0.41 & 53 & 47 & 0.88 & 79 & 21 & 0.27 \\
\hline $1997-98$ & 62 & 38 & 0.61 & 35 & 65 & 1.86 & 98 & 2 & 0.02 \\
\hline Growth (\%) & -15.07 & 40.74 & 64.86 & -16.67 & 12.07 & 34.78 & 32.43 & -92.31 & -94.29 \\
\hline
\end{tabular}

\begin{tabular}{l|ccc|ccc|ccc} 
& \multicolumn{3}{|c|}{ HDI } & \multicolumn{3}{c|}{ HPI } & \multicolumn{3}{c}{ CHDWORK } \\
\hline & Within & Between & KZ index & Within & Between & KZ index & Within & Between & KZ index \\
\hline $1981-82$ & 33 & 67 & 2.03 & 37 & 63 & 1.70 & 93 & 7 & 0.08 \\
$1991-92$ & 31 & 69 & 2.23 & 32 & 68 & 2.13 & 97 & 3 & 0.03 \\
Growth (\%) & -6.06 & 2.99 & 9.85 & -13.51 & 7.94 & 25.29 & 4.30 & -57.14 & -62.50
\end{tabular}

\begin{tabular}{l|ccc|} 
& \multicolumn{3}{|c|}{ U5MORT } \\
\hline & Within & Between & KZ index \\
\hline $1981-82$ & 67 & 33 & 0.49 \\
$1991-92$ & 79 & 21 & 0.27 \\
Growth (\%) & 17.91 & -36.36 & -44.90
\end{tabular}

There is considerable polarisation around the dimension of literacy. The betweengroup inequality (MKZ index) around this dimension has increased by more than $44 \%$ and this coupled with a drop in within-group inequality has resulted in the $\mathrm{KZ}$ index increasing by a staggering growth rate of nearly $178 \%$ over the period. This is a strong indication of polarisation around this dimension. The dimension of female literacy depicts an interesting picture. The $\mathrm{KZ}$ index is less than 1 in the beginning and rapidly increases through the period resulting in the index increasing by nearly five folds. The combined decrease in within-group inequality and increase in between-group inequality, which is again very high, indicates the increase in polarisation around this dimension. The pupil-teacher ratio at the secondary school level, a measure of the quality of education, starts with a rather low value for the $\mathrm{KZ}$ 
index and fluctuates around this low value. Despite the growth in the KZ index there is little evidence of polarisation around this dimension.

Urbanisation is an interesting dimension from a theoretical point of view as it is often argued in the literature to be coupled with industrialisation and growth. The results in Table 9 do not provide any evidence of polarisation around this pole for Indian states. However, its high growth rate is notable despite the $\mathrm{KZ}$ index being still less than 1 indicating that while the source of inequality is more within groups the between-group component has been increasing over time steadily.

The results for poverty dimension are interesting. The KZ index is originally high and above 1. After an initial increase it drops significantly before increasing considerably in 1997-98. Over the period the drop in within-group inequality combined with an increase in the MKZ index has resulted in a remarkable increase in the KZ index. Bearing in mind that the initial value of this index was more than 1 the growth rate in this index is alarming. Once again a significant degree of polarisation has taken place around this dimension.

Polarisation around the dimension of poverty spins off an interesting question. Have the poverty reduction policies been in the right direction for reducing polarisation around this dimension? We took a broad policy measure for attempting to throw some light on the above question: the percentage of plan expenditure in the rural and social sector. ${ }^{14}$ It would be interesting to see if polarisation around this dimension is in harmony with the same around the poverty dimension. The results are remarkable. The KZ index from an initially low value is reduced to nearly zero indicating that only within-group inequality contributed to the total inequality. On its own we interpret this as the policy stance being remarkably correct. However, in conjunction with the results for poverty dimension one may conclude that the policy stance with respect to polarisation has been remarkably correct though not adequate.

The remainder of Table 9 presents the results for a number of composite, social and health dimensions but for a shorter time period due to data limitation. Polarisation

\footnotetext{
${ }^{14}$ Fan et al. (1999) state that public expenditure in rural infrastructure has had a positive effect on the reduction of poverty in India.
} 
around the dimension of Human Development Index (HDI) is particularly high where the $\mathrm{KZ}$ index has an initial high value and increases over the period, a clear sign of a remarkable polarisation around this dimension. The dimension of Human Poverty Index (HPI) is also a significant dimension in this respect. ${ }^{15}$ The decrease in withingroup inequality combined with an increase in between-group inequality has resulted in the $\mathrm{KZ}$ index to growing by more than $25 \%$ from an initially high value. In Estaban and Ray's terminology the identification and alienation components of polarisation have both increased, the poorer states have got closer to each other as the better off states have but the gulf between these two groups has widened.

The other possible dimensions tested were the percentage of working children in the age group of 5 to 14 (CHDWRK) reflecting a mixture of factors including the social attitude, poverty and deprivation in a broader sense. There is little explanation for polarisation around this dimension most of the inequality around this dimension is from the within-group source. The dimension of under 5 mortality rate (U5MORT) as an indicator of health and other related issues is the last one we tried. The results show a drop in polarisation from an initially low level. Once again there seems to be little polarisation around this dimension.

In addition to dynamic analysis we also tried the above dimensions in a static fashion. More precisely we used the value of the dimension at the initial period for grouping the states through the period into above the average value for India and below. As mentioned before this corresponds to the proposition of the effect of initial conditions on convergence discussed in the literature.

The results are presented in Table A1 in Appendix A and are broadly similar to those for the dynamic analysis with some differences. The results for literacy dimension are very similar but with some differences for the middle years in the period. Those for the female literacy dimension have the same direction but of a lower magnitude. The pupil teacher ratio dimension is again immaterial but the growth is in the opposite direction from a very low base. The urbanisation dimension produces more or less the same results and the same goes for the poverty dimension. The rural and social

\footnotetext{
${ }^{15}$ Both HDI and HPI are the well-known UNDP’s indices computed for the states of India.
} 
expenditure dimension shows a positive growth as compared to a negative growth in the dynamic analysis, however, this is from a very low base and hence the main source of inequality is still the within-group. The dimensions of CHDWRK and U5MORT produce similar results and remain immaterial to polarisation. The results for HDI and HPI are identical (hence not presented in the appendix), as there seems to be no group change for the states in the decade.

We also applied the above analysis to out consumption expenditure variable (PCCE) and the results are presented in Table $10 .{ }^{16}$

Table 10. Dynamic polarisation of states for PCCE - percentage within-group and between-group contributions to total inequality and KZ index

\begin{tabular}{|c|c|c|c|c|c|c|c|c|c|}
\hline \multirow[t]{2}{*}{ Year } & \multicolumn{3}{|c|}{ Literacy } & \multicolumn{3}{|c|}{ Female Literacy } & \multicolumn{3}{|c|}{ Pupil-Teacher ratio } \\
\hline & Within & Between & $\mathrm{KZ}$ index & Within & Between & $\mathrm{KZ}$ index & Within & Between & $\mathrm{KZ}$ index \\
\hline 1983 & 58 & 42 & 0.72 & 71 & 29 & 0.41 & 80 & 20 & 0.25 \\
\hline 1993-1994 & 59 & 41 & 0.69 & 59 & 41 & 0.69 & 88 & 12 & 0.14 \\
\hline 1999-2000 & 50 & 50 & 1.00 & 53 & 47 & 0.89 & 57 & 43 & 0.75 \\
\hline \multirow[t]{3}{*}{ Growth (\%) } & -13.79 & 19.05 & 38.89 & -25.35 & 62.07 & 117.11 & -28.75 & 115.00 & 200.00 \\
\hline & \multicolumn{3}{|c|}{ Urbanisation } & \multicolumn{3}{|c|}{ Poverty } & \multicolumn{3}{|c|}{$\begin{array}{l}\text { Rural \& Social } \\
\text { Expenditure }\end{array}$} \\
\hline & Within & Between & $\mathrm{KZ}$ index & Within & Between & $\mathrm{KZ}$ index & Within & Between & $\mathrm{KZ}$ index \\
\hline 1983 & 87 & 13 & 0.15 & 36 & 64 & 1.78 & 69 & 31 & 0.45 \\
\hline 1993-1994 & 86 & 14 & 0.16 & 39 & 61 & 1.56 & 83 & 17 & 0.20 \\
\hline 1999-2000 & 89 & 11 & 0.12 & 45 & 55 & 1.22 & 99 & 1 & 0.01 \\
\hline Growth (\%) & 2.30 & -15.38 & -17.29 & 25.00 & -14.06 & -31.25 & 43.48 & -96.77 & -97.77 \\
\hline
\end{tabular}

\begin{tabular}{l|ccc|ccc|ccc} 
& \multicolumn{3}{|c|}{ HDI } & \multicolumn{3}{c|}{ HPI } & \multicolumn{2}{c}{ CHDWRK } \\
\hline & Within & Between & KZ index & Within & Between & KZ index & Within & Between & KZ index \\
\hline 1983 & 47 & 53 & 1.13 & 50 & 50 & 1.00 & 96 & 4 & 0.04 \\
$1993-1994$ & 39 & 61 & 1.56 & 39 & 61 & 1.56 & 91 & 9 & 0.10 \\
Growth (\%) & -17.02 & 15.09 & 38.05 & -22.00 & 22.00 & 56.00 & -5.21 & 125.00 & 150.00
\end{tabular}

\begin{tabular}{l|ccc|} 
& \multicolumn{3}{|c|}{ U5MORT } \\
\hline & Within & Between & KZ index \\
\hline 1983 & 74 & 26 & 0.35 \\
$1993-1994$ & 83 & 17 & 0.20 \\
Growth (\%) & 12.16 & -34.62 & -42.86
\end{tabular}

With respect to the dimension of literacy there is a considerable increase in betweengroup inequality and the $\mathrm{KZ}$ index indicates a growth rate of nearly $39 \%$ in polarisation over the period caused by a decrease in the within-group and an increase in between-group inequality. The dimension of female literacy also gives similar

\footnotetext{
${ }^{16}$ The same for IIAPCCE were also computed but not presented as the results are very similar.
} 
results as before with a growth rate of $117 \%$ over the period. The pupil-teacher ratio results for consumption are different to those for PCNSDP. Although it starts from a low base for the $\mathrm{KZ}$ index it grows rapidly at the rate of $200 \%$ over the period. The contribution of the between-group inequality to total at the end of period is nearly approaching that of the within-group. As in the previous dimensions the increase in between-group inequality is coupled with a decrease in inequality amongst the members of the group: a clear indication of polarisation around these dimensions.

The results for urbanisation do not provide any evidence of polarisation around this pole for Indian states. On the contrary the $\mathrm{KZ}$ index and its relevant components all point to a drop in polarisation. The results for poverty dimension are interesting. The $\mathrm{KZ}$ index is originally high and above 1 . Over the period there is a drop in this index but it has remained still above 1 indicating that at the end of the concerned period between-group inequality is still higher than within-group inequality. Once again we were interested to see possible polarisation around the policy indicator of the percentage of plan expenditure in rural and social sectors. The results are similar to those for the production indicator. The $\mathrm{KZ}$ index from an initially low value is reduced to nearly zero indicating that only the within-group inequality contributed to the total inequality. This provides further support for our previous conclusion related to the correct policy stance but inadequate

Polarisation around the human development index (HDI) is considerable and increasing. The KZ index is above 1 and has increased by more than 38\% over the period. Similarly polarisation around the dimension of human poverty index (HPI) has increased remarkably. A decrease in within-group and an increase in between-group inequality has resulted in a 56\% increase in the $\mathrm{KZ}$ index over the period from an initial value of 1 in 1983. There seems to be clear signs of polarisation around the latter two dimensions.

There is little evidence of polarisation around the dimension of CHDWRK despite its remarkable growth over the period; still 91\% of total inequality around this dimension comes from the within-group inequality. The dimension of U5MORT shows a drop in polarisation from an initially low level; once again no evidence of polarisation around this dimension. 
The results for the static analysis for PCCE are presented in Table A2 in Appendix A. Once again in this table we have treated the dimensions as initial conditions. There is little change in results for the dimension of literacy, however, female literacy dimension produces considerably less growth in the $\mathrm{KZ}$ index and remains considerably below 1 indicating little polarisation around this dimension. The dimension of pupil-teacher ratio at secondary level produces totally different results indicating a negative growth in the $\mathrm{KZ}$ index as opposed to a high positive growth when this dimension was treated dynamically. For the urbanisation dimension we have now positive growth for the KZ index though from an initially low level of between-group inequality as before. Polarisation around the dimension of poverty follows the same pattern with less negative growth in the KZ index but still with a relatively high value for the index. The rural and social expenditure dimension shows some inequality accounted for by between-group inequality but relative to withingroup contribution. This is still low. The HDI and HPI dimensions produce the same results as the dynamic analysis, hence not provided. The CHDWRK dimension still shows very low KZ index as before though U5MORT demonstrates a positive growth in the $\mathrm{KZ}$ index as opposed to a negative growth in the dynamic analysis.

The results for dynamic and static analyses are almost similar with the exception of those for the dimensions of pupil-teacher ratio, urbanisation, CHDWRK and U5MORT. One is tempted to argue that within the evolving socio-economic sphere of inequality the dynamism of change and causality reflects a more realistic picture, however, all these dimensions depict very low between-group inequality and hence do not reflect a considerable polarisation around them in both analyses.

The evidence seems to support the proposition that polarisation with respect to production and consumption may have taken place around the dimensions of literacy, female literacy, poverty, HDI and HPI.

Finally it should be pointed out that our study did not address the issue of groupspecific pattern and extent of inequality which is worthy of a separate research. 


\section{Conclusion}

There has been little evidence of convergence taking place amongst the states of India over the period of study. Spatial inequality in production and consumption in India have grown at considerable rates. Our results provide more support for those theoretical models arguing for regional divergence rather than convergence. This is in agreement with a number of empirical studies on disparities in India (for example Dreze and Sen 1995, Datt and Ravallion 1993 and 1998 Ravallion and Datt 2002, Mehta and Shah 2003). Furthermore the trend seems to be in the direction of more divergence.

However, it should be noted that the time span of our analysis is of medium term length while the advocates of convergence argue in the long-run context. Nevertheless there is little evidence of a move in the direction of convergence.

Furthermore, the results show that there seems to be an increase in polarisation over the period of the study. One may relate the high level of polarisation to the discussion of the convergence clubs in the literature as the boundary between the convergence clubs and polarisation is rather thin when we have fewer convergence clubs. However, given the fewer number of cases (states) in our study as opposed to the higher number of cases in cross-country studies the emergence of numerous convergence clubs amongst the Indian states seems to be less likely. It seems more likely to be the case of poorer and richer states diverging and clustering. Polarisation seems to be taking place around the dimensions of literacy, female literacy, poverty and composite indices of human development and human poverty, though not exclusive to these dimensions.

It would be fair to say that in the light of the experience of other developing countries discussed in section I and the results of this study if the existing trend remains the same it seems more likely that the states of India will grow more apart and the disparities will get wider through time. 


\section{Appendix A}

Table A1. Static polarisation of states for PCNSDP - percentage within-group and between-group contributions to total inequality and KZ index

\begin{tabular}{|c|c|c|c|c|c|c|c|c|c|}
\hline \multirow[t]{2}{*}{ Year } & \multicolumn{3}{|c|}{ Literacy } & \multicolumn{3}{|c|}{ Female Literacy } & \multicolumn{3}{|c|}{ Pupil-Teacher ratio } \\
\hline & Within & Between & $\mathrm{KZ}$ index & Within & Between & $\mathrm{KZ}$ index & Within & Between & $\mathrm{KZ}$ index \\
\hline 1981-82 & 48 & 52 & 1.08 & 68 & 32 & 0.47 & 83 & 17 & 0.20 \\
\hline $1983-84$ & 48 & 52 & 1.08 & 66 & 34 & 0.52 & 79 & 21 & 0.27 \\
\hline $1991-92$ & 38 & 62 & 1.63 & 62 & 38 & 0.61 & 83 & 17 & 0.20 \\
\hline $1993-94$ & 33 & 67 & 2.03 & 56 & 44 & 0.79 & 86 & 14 & 0.16 \\
\hline $1997-98$ & 25 & 75 & 3.0 & 52 & 48 & 0.92 & 86 & 14 & 0.16 \\
\hline \multirow[t]{3}{*}{ Growth (\%) } & -47.92 & 44.23 & 177.78 & -23.53 & 50.00 & 95.74 & 3.61 & -17.64 & -20.00 \\
\hline & \multicolumn{3}{|c|}{ Urbanisation } & \multicolumn{3}{|c|}{ Poverty } & \multicolumn{3}{|c|}{$\begin{array}{l}\text { Rural \& Social } \\
\text { Expenditure }\end{array}$} \\
\hline & Within & Between & $\mathrm{KZ}$ index & Within & Between & $\mathrm{KZ}$ index & Within & Between & $\mathrm{KZ}$ index \\
\hline 1981-82 & 73 & 27 & 0.37 & 42 & 58 & 1.38 & 74 & 26 & 0.35 \\
\hline $1983-84$ & 63 & 37 & 0.59 & 38 & 62 & 1.63 & 79 & 21 & 0.27 \\
\hline 1991-92 & 68 & 32 & 0.47 & 38 & 62 & 1.63 & 74 & 26 & 0.35 \\
\hline $1993-94$ & 64 & 36 & 0.56 & 39 & 61 & 1.56 & 71 & 29 & 0.41 \\
\hline $1997-98$ & 60 & 40 & 0.67 & 39 & 61 & 1.56 & 72 & 28 & 0.39 \\
\hline Growth (\%) & -17.81 & 48.15 & 81.08 & -7.14 & 5.17 & 13.04 & -2.70 & 7.69 & 11.43 \\
\hline
\end{tabular}

\begin{tabular}{l|ccc|ccc|} 
& \multicolumn{3}{|c|}{ CHDWRK } & \multicolumn{3}{c|}{ U5MORT } \\
\hline & Within & Between & KZ index & Within & Between & KZ index \\
\hline $1981-82$ & 93 & 7 & .08 & 67 & 33 & 0.49 \\
$1991-92$ & 93 & 7 & .08 & 63 & 37 & 0.59 \\
Growth (\%) & 0 & 0 & 0 & -5.97 & 12.12 & -20.41
\end{tabular}


Table A2. Static polarisation of states for PCCE - percentage within-group and between-group contributions to total inequality and $\mathrm{KZ}$ index

\begin{tabular}{|c|c|c|c|c|c|c|c|c|c|}
\hline \multirow[t]{2}{*}{ Year } & \multicolumn{3}{|c|}{ Literacy } & \multicolumn{3}{|c|}{ Female Literacy } & \multicolumn{3}{|c|}{ Pupil-Teacher ratio } \\
\hline & Within & Between & $\mathrm{KZ}$ index & Within & Between & KZ index & Within & Between & $\mathrm{KZ}$ index \\
\hline 1983 & 58 & 42 & 0.72 & 71 & 29 & 0.41 & 80 & 20 & 0.25 \\
\hline 1993-1994 & 57 & 43 & 0.75 & 70 & 30 & 0.43 & 80 & 20 & 0.25 \\
\hline $1999-2000$ & 50 & 50 & 1.00 & 66 & 34 & 0.52 & 82 & 18 & 0.22 \\
\hline \multirow[t]{3}{*}{ Growth (\%) } & -13.79 & 19.05 & 38.89 & -7.04 & 17.24 & 26.83 & 2.50 & -10.00 & -12.00 \\
\hline & \multicolumn{3}{|c|}{ Urbanisation } & \multicolumn{3}{|c|}{ Poverty } & \multicolumn{3}{|c|}{$\begin{array}{l}\text { Rural \& Social } \\
\text { Expenditure }\end{array}$} \\
\hline & Within & Between & $\mathrm{KZ}$ index & Within & Between & KZ index & Within & Between & KZ index \\
\hline 1983 & 87 & 13 & 0.15 & 36 & 64 & 1.78 & 69 & 31 & 0.45 \\
\hline 1993-1994 & 86 & 14 & 0.16 & 38 & 62 & 1.63 & 65 & 35 & 0.54 \\
\hline $1999-2000$ & 83 & 17 & 0.20 & 37 & 63 & 1.70 & 62 & 38 & 0.61 \\
\hline \multirow[t]{3}{*}{ Growth (\%) } & -4.60 & 30.77 & 33.33 & 2.78 & -1.56 & -4.49 & -10.14 & 22.58 & 35.56 \\
\hline & \multicolumn{3}{|c|}{ CHDWRK } & \multicolumn{3}{|c|}{ U5MORT } & & & \\
\hline & Within & Between & $\mathrm{KZ}$ index & Within & Between & $\mathrm{KZ}$ index & & & \\
\hline 1983 & 96 & 4 & 0.04 & 74 & 26 & 0.35 & & & \\
\hline $1993-1994$ & 95 & 5 & 0.05 & 69 & 31 & 0.45 & & & \\
\hline Growth (\%) & -1.04 & 25.00 & 25.00 & -6.76 & 19.23 & 28.57 & & & \\
\hline
\end{tabular}




\section{References}

Barro, R. and Sala-i-Martin, X. (1992) 'Convergence', Journal of Political Economy, Vol. 100, 223-51.

Barro, R. and Sala-i-Martin, X. (1995) 'Economic Growth', McGraw Hill, New York.

Baumol W.J. (1986) 'Productivity growth, convergence and welfare: What the longrun data show’, American Economic Review 76, 1072-85.

Baumol W.J. and Wolff E.N. (1988) 'Productivity growth, convergence and welfare: Reply’, American Economic Review 78, 1155-59.

Boyer, R. (1996) 'The Convergence Hypothesis Revisited: Globalisation but Still a Century of Nations?' In S. Gerger and R. Dore (eds) 'National Diversity and Global Capitalism’ Cornell University Press, Itacha and London.

Chatterji, M. and Dewhurst, J.H. (1996) 'Convergence clubs and relative economic performance in Great Britain, 1977-1991’, Regional Studies 30, 31-40.

Chatterji, M. (1992) 'Convergence clubs and endogenous growth', Oxford Review of Economic Policy 8, 57-69.

Coulombe, S. (2003) 'Human Capital, Urbanization, and Canadian Provincial Growth’, Regional Studies, Volume 37(3), 241-252.

Cowell, F. (1995) ‘ Measuring Inequality’ ( $2^{\text {nd }}$ edition), Prentice Hall/Harvester Wheatsheaf.

Datt, G. and M. Ravallion (1993) 'Regional Disparities, Targeting, and Poverty in India”, in Michael Lipton and J. van Der Gaag (eds) 'Including the Poor'. World Bank, Wasgington D.C.

Datt, G. and M. Ravallion (1998) 'Why Have Some Indian States Done better than Others at Reducing Rural Povert?’ Economica, Vol. 65, 17-38.

Dreze J. and A. Sen (1995) 'India: Economic Development and Social Opportunity', Oxford University press.

Dreze J. and P.V. Srinivasan (1996) 'Poverty in India: Regional Estimates 1987-8', Discussion Paper No. 70, London School of Economics.

Dunford, M. (1988), 'Capital, the state and regional development'. London, Pion.

Dunford, M. and A. Smith (2000) 'Catching up or Falling Behind? Economic Performance and Regional Trajectories in the "New Europe”, Economic Geography, 76(2), 169-195. 
Emmanuel, A. 'Unequal Exchange: A Study of the Imperialism of Trade', London, New Left Books.

Esteban, J-M. and D. Ray (1994), 'On the Measurement of Polarisation' Econometrica, 62(4), 819-851.

Fan, S., P. Hazell and S. Thorat (1999), 'Linkages between Government Spending, Growth, and Poverty in Rural India', International Food Policy Research Institute, Research Report 10, Washington D.C.

Fedorov, L. (2002) 'Regional Inequality and Regional Polarization in Russia, 199099’, World Development, 30(3), 443-456.

Harvey, D. 'The limits to capital', Oxford, Balckwell.

HDNUNDP (Human Development Network and United Nations Development programme) (1997) 'Philippine Human Development Report 1997', HNDUNDP.

Kaldor, N. (1970) 'The case for regional policies', Scottish Journal of Political Economy, November, 337-48.

Kaldor, N. (1981) 'The role of increasing returns, technical progress and cumulative causation in the theory of international trade and economic growth in F. Targetti and A. Thirwall (eds) 'The Essential Kaldor', Duckworth, London.

Kanbur, R. and Zhang, X. (1999) 'Which regional inequality? The evolution of ruralurban and inland-coastal inequality in China from 1983 to 1995', Journal of Comparative Economics, 27(4), 686-701.

Kay, Ch. (1989) 'Latin American Theories of Development and Underdevelopment', Routledge, London.

Lucas, R.E. (1988) 'On the mechanics of economic development', Journal of Monetary Economics, 22: 3-42.

Mankiw, N. G., D.Romer and D.N. Weil (1992), 'A Contribution to the Empirics of Economic Growth’, Quarterly Journal of Economics 107(2): 407-37.

Martin, R. and Sunley, P. (1998) 'Slow Convergence? The New Endogenous Growth Theory and Regional Development’, Economic Geography, 74: 201-227.

Mehta, A. K. and A. Shah (2003) 'Chronic Poverty in India: Incidence, Causes and Policies’, World Development, 31(3): 491-511.

Milanovic, B. (1997) 'A simple way to calculate the Gini coefficient, and some implications’, Economic Letters, 56: 45-49.

Myrdal, G. (1957) 'Economic theory and underdeveloped regions', Duckworth, London. 
Noorbakhsh, F. (1998) 'A Modified Human Development Index', World Development, 26(3), 517-528.

Noorbakhsh, F. (1999) 'Standards of Living, Human Development Indices and Structural Adjustments in Developing Countries: An Empirical Investigation', Journal of International Development, Vol.11, 151-175.

Noorbakhsh, F. (2002) 'Human Development and Regional Disparities in Iran: A Policy Model’, Journal of International Development, Vol.14, 927-949.

Noorbakhsh, F. (2003) 'Human Development, Poverty and Disparities in the States of India', paper presented at the United nations University/WIDER conference on 'Inequality, Poverty and Human Well-being', 30-31 May 2003, Helsinki, Finland.

PBOUNDP (Plan and Budget Organisation of the Islamic Republic of Iran and United Nations Development programme) (1999) Human Development Report of the Islamic Republic of Iran 1999, Plan and Budget Organisation of the Government of Iran and the United Nations, Tehran.

PCGI (Planning Commission Government of India) (2002) 'National Human Development Report 2001’ Planning Commission of India, New Delhi.

Pyatt, G., C-N. Chen and J. Fei (1980) 'The Distribution of Income by Factor Components’ Quarterly Journal of Economics, November, 451-473.

Quah, D. (1993) 'Empirical cross section dynamics in economic growth', European Economics, 37:35-46.

Ravallion, M. and G. Datt (2002) 'Why has economic growth been more pro-poor in some states in India than others?' Journal of Development Economics, 68, 381-400.

Riskin, C. (1998) ‘China’s Political Economy’, Oxford University Press.

Romer, P. (1986) 'Increasing returns and long-run growth', Journal of Political Economy, 94, 1002-37.

Sala-i-Martin, X. (1996) 'The classical approach to convergence analysis'. Economic Journal, 106, 1019-36.

Shorroks, A. (1980) 'The class of additively decomposable inequality measures', Econometrica, 48(3), 613-625.

Shorroks, A. (1984) 'Inequality decomposition by population subgroups', Econometrica, 52(6), 1369-1385.

Smith, D. (1975) 'Neoclassical growth models and regional growth in the US', Journal of Regional Science, Vol. 15, 165-81. 
UNDP et al. (United Nations Development programme, Poverty Reduction Forum and Institute of Development Studies) (1998) 'Zimbabwe Human Development Report 1998', UNDP, Harare, Zimbabwe.

Vanderpuye-Orgle, J. (2002) 'Spatial Inequality and Polarisation in Ghana, 1987-99' Paper presented at the Conference on Spatial Inequalities in Africa, Centre for the Study of African Economies, University of of Oxford, 21-22 September 2002.

Wei, Y. D. (1999) 'Regional Inequality in China', Progress in Human Geography, Vol23, No. 1, 48-58.

Wei, Y. D. (2000) 'Regional Development in China: States, Globalisation, and Inequality’ Routledge, London.

Wei, Y. D. and S. Kim (2002) 'Widening Inter-County Inequality in Jiangsu Province, China, 1950-95’, Journal of Development Studies, Vol 38(6), 142-164.

Wolfson, M. C. (1994) 'When Inequalities Diverge', American Economic Review', 84(2), 353-358.

Wolfson, M. C. (1997) 'Divergent Inequalities: Theory and Empirical Results', Review of Income and Wealth, 43(4), 401-421.

Zhang, X. and R. Kanbur (2001) 'What Difference Do Polarisation Measures Make? An Application to China’ Journal of Development Studies, Vol 37(3), 85-98. 